\title{
Alpha-Fetoprotein and Novel Tumor Biomarkers as Predictors of Hepatocellular Carcinoma Recurrence after Surgery: A Brilliant Star Raises Again
}

\author{
Quirino Lai, ${ }^{1}$ Fabio Melandro, ${ }^{1}$ Rafael S. Pinheiro, ${ }^{2}$ Andrea Donfrancesco, ${ }^{3}$ Bashir A. Fadel, ${ }^{4}$ \\ Giovanni B. Levi Sandri, ${ }^{1}$ Massimo Rossi, ${ }^{1}$ Pasquale B. Berloco, ${ }^{1}$ and Fabrizio M. Frattaroli ${ }^{1}$ \\ ${ }^{1}$ Department of General Surgery and Organ Transplantation, Sapienza University of Rome, Umberto I Policlinic of Rome, \\ Viale del Policlinico 155 00161, Rome, Italy \\ ${ }^{2}$ Department of Liver Transplantation, University of São Paulo, Av Dr Eneas de Carvalho Aguiar 255, 05403-010 São Paulo, Brazil \\ ${ }^{3}$ Department of Surgery, Arzignano, Hospital, ULSS5 Ovest Vicentino, Via Kennedy 2 36071, Arzignano, Italy \\ ${ }^{4}$ General Surgery Department, Assiut University Hospital, Assiut 71515, Egypt
}

Correspondence should be addressed to Quirino Lai, lai.quirino@libero.it

Received 8 April 2012; Revised 3 May 2012; Accepted 4 May 2012

Academic Editor: Nikki P. Lee

Copyright ( $) 2012$ Quirino Lai et al. This is an open access article distributed under the Creative Commons Attribution License, which permits unrestricted use, distribution, and reproduction in any medium, provided the original work is properly cited.

Alpha-fetoprotein (AFP), des- $\gamma$-carboxy prothrombin (DCP), and lens culinaris agglutinin-reactive fraction of AFP (AFP-L3) have been developed with the intent to detect hepatocellular carcinoma (HCC) and for the surveillance of at-risk patients. However, at present, none of these tests can be recommended to survey cirrhotic patients at risk for HCC development because of their suboptimal ability for routine clinical practice in HCC diagnosis. Starting from these considerations, these markers have been therefore routinely and successfully used as predictors of survival and HCC recurrence in patients treated with curative intent. All these markers have been largely used as predictors in patients treated with hepatic resection or locoregional therapies, mainly in Eastern countries. In recent studies, AFP has been proposed as predictor of recurrence after liver transplantation and as selector of patients in the waiting list. Use of AFP modification during the waiting list for LT is still under investigation, potentially representing a very interesting tool for patient selection. The development of a new predictive model combining radiological and biological features based on biological markers is strongly required. New genetic markers are continuously discovered, but they are not already fully available in the clinical practice.

\section{Alpha-Fetoprotein: A Historical Background}

Alpha-fetoprotein (AFP) has been considered for a long time the ideal serological marker for detecting hepatocellular carcinoma (HCC).

It is well known that persistently elevated AFP levels are related to the presence of HCC and that its determination can be helpful for a better definition of at-risk patients (i.e., patients with a history of cirrhosis) [1]; hence, AFP is the most widely tested biomarker in HCC.

Historically, AFP has been mainly tested in the diagnostic mode rather than for HCC surveillance after any type of tumor treatment; consequently, AFP has been introduced as a variable in the flowcharts used for HCC diagnosis in both Europe and the USA $[2,3]$.

However, when combined with ultrasounds (US), AFP levels have shown to be able to only provide additional detection in $6-8 \%$ of not previously identified cases [4].

Several aspects are at the basis of the suboptimal performance of AFP as a serological test for HCC diagnosis.

Firstly, HBV or HCV infection and exacerbation of underlying liver disease determine fluctuating levels of AFP in patients with cirrhosis $[5,6]$.

Secondly, only a small proportion of early-stage HCCs (10-20\%) present with abnormal AFP serum levels [7]. 
When used as a diagnostic test, AFP value of $20 \mathrm{ng} / \mathrm{mL}$ shows good sensitivity but low specificity, whilst the higher cut-off value of $200 \mathrm{ng} / \mathrm{mL}$ presents a high specificity but a sensitivity dropping to $22 \%$ [8].

\section{The Demise of a Brilliant Star: AFP Is Removed from Diagnostic Flowcharts}

Starting from these considerations, AFP has not been considered anymore a valid test to recommend for the survey of patients at risk of developing HCC.

In a recent publication, Forner et al. have poetically defined AFP discontinuation as marker for HCC diagnosis as a "demise of a brilliant star" [9].

Looking at the flowcharts used for HCC diagnosis, the most recent ones consider only radiological exams, eventually combining biopsy in the diagnostic process in the presence of tumors with uncertain behavior or very small dimensions (Figure 1) [4].

\section{Introduction of New Biomarkers in HCC Diagnosis}

Apart from AFP, several novel markers have been developed in the last years with the intent to improve the diagnostic power and to better detect HCC in the population of cirrhotic patients.

Among them, des- $\gamma$-carboxy prothrombin (DCP) and lens culinaris agglutinin-reactive fraction of AFP (AFP-L3) have been more largely investigated, in both Western and Eastern experiences $[10,11]$.

(1) DCP, also called prothrombin induced by vitamin $\mathrm{K}$ absence (PIVKA), is an abnormal prothrombin molecule generated as a result of an acquired defect in the posttranslational carboxylation of the prothrombin precursor in malignant cells: this decarboxylated prothrombin is also produced in the presence of vitamin K deficiency [12].

The exact cause of DCP production in HCC has not been completely understood yet. Several possible explanations have been proposed: (a) activity of carboxylase enzymes declines into the tumor tissue; (b) a splice variant of carboxylase is present in DCP-producing HCC cells; (c) availability of vitamin $\mathrm{K}$ declines in the tumor as the result of an abnormal vitamin K metabolism [13].

In recent studies, vitamin $\mathrm{K}$ administration has been correlated with a dose-dependent reduction of DCP production $[14,15]$, suggesting that vitamin $\mathrm{K}$ may even present a biological effect against the tumor [15].

Clinical usefulness of DCP in HCC detection has been recently tested, showing major sensitivity and specificity respect to AFP $[16,17]$.

(2) AFP-L3 is an isoform of AFP and it is reported as the percentage of AFP-L3 over the total AFP level. Previous studies have identified $10 \%$ as the cut-off for the presence of HCC [18].

Many studies have investigated the role of AFP-L3, alone or in combination with AFP and DCP, as a marker for the surveillance of patients at risk for HCC [18-22].
Use of AFP-L3, despite its major diffusion in Eastern countries, has recently improved also in Western centres [1922].

Contrasting results have been obtained comparing AFPL3 with the other biomarkers: in a recent study, DCP has showed a higher sensitivity ( $87 \%$ versus $56 \%$ ) and a superior ability in detecting patients without HCC [18], whilst in a US large phase 2 biomarker case-control study, AFP has been the most sensitive marker [19].

A prospective US study has shown a correlation between portal vein invasion and AFP-L3\%, whilst DCP has been significantly associated with HCC metastasis [22].

However, despite the great interest related to the development of new biomarkers, DCP and AFP-L3 seem not to present markedly improved abilities in detecting HCC respect to AFP, mainly in the presence of early tumoral pathology.

Both DCP and AFP-L3 fraction levels have been associated with portal vein invasion and advanced tumoral stage, a fact that prevents the usage of these markers for early detection $[23,24]$.

Consequently, the new serum markers, used alone or in combination, have not offered any substantial advantage with respect to AFP: at present, none of tests used for HCC detection can be recommended to survey cirrhotic patients at risk for HCC development [4].

\section{The Star Rises Again: AFP as Predictor of Survival and Tumor Recurrence}

In very recent years, AFP has been proposed as a predictor of patient survival and tumor recurrence after surgery, locoregional therapies, and systemic chemotherapy [25-29].

This new role derives from the strong correlation detected between AFP values, tumor dimensions, and microvascular invasion, all well-known predictors of HCC recurrence [30].

In fact, AFP represents a surrogate of tumoral activity and vascular invasiveness: AFP-mRNA dosage, used as a marker of HCC cell dissemination into the circulation, represents a further confirmation of this correlation $[31,32]$.

Many studies have investigated the best AFP measurement to consider for patient selection: in a recent large experience performed on 6817 US patients listed for liver transplantation (LT) with a diagnosis of HCC, last AFP before surgery has resulted as one of the strongest variables for patient selection before LT [25]. Similar results have been observed in a study from Italy, in which AFP before LT has been the unique independent risk factor for HCC recurrence [26].

Apart from the moment of AFP determination, a great debate also exists on the best AFP threshold value to be used. Several cut-offs have been proposed (210, 400 and $1000 \mathrm{ng} / \mathrm{mL})[26,33,34]$, but none of them has already obtained a definitive international validation.

In two studies from France and Canada, the velocity of AFP increase has been suggested as the best predictor of HCC recurrence after LT. However, also this new parameter and its 


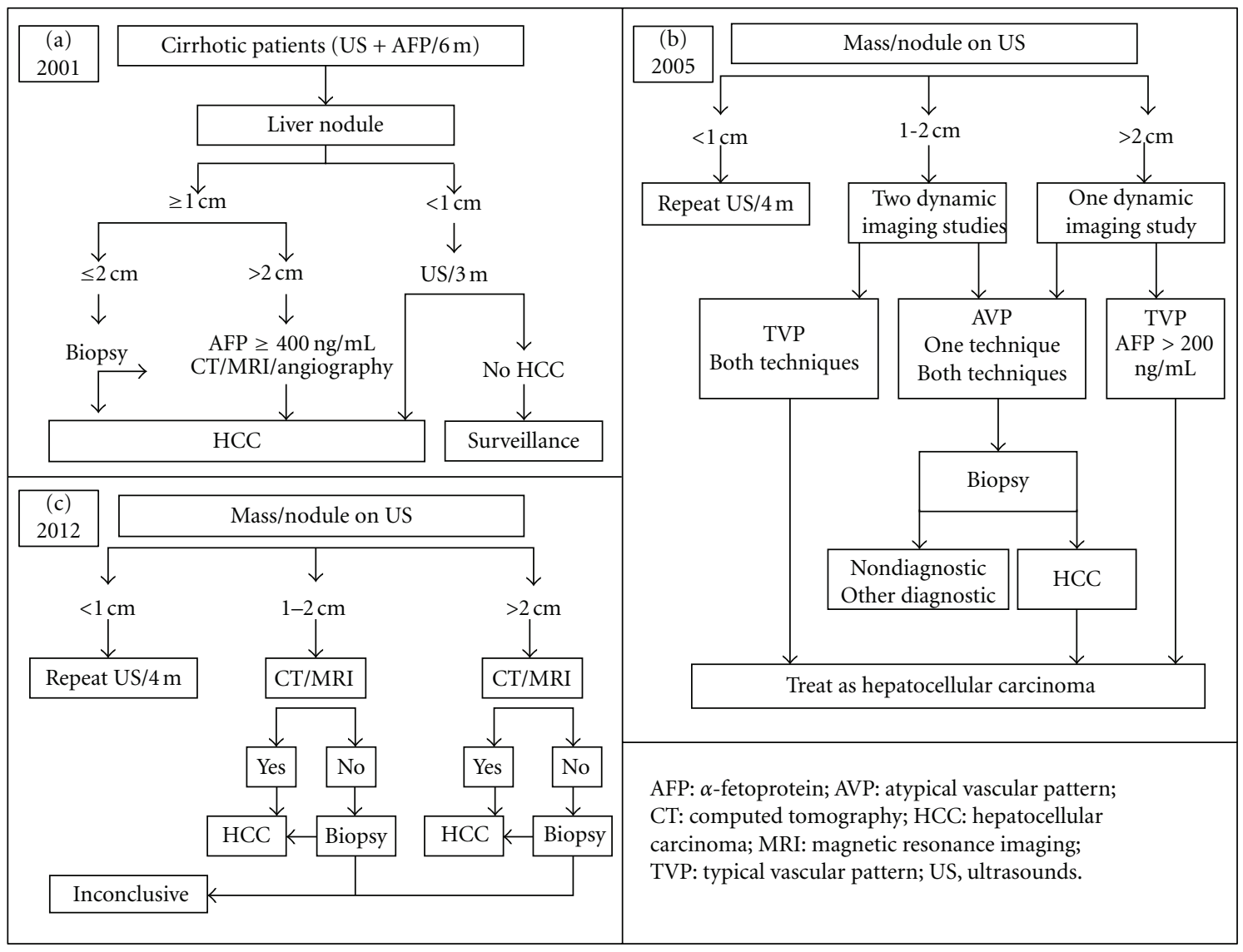

FIGURE 1: Development of different European and US flow charts proposed in the last decade for the diagnosis of HCC. AFP has progressively disappeared from the variables used for the diagnosis. Flow-chart (a): from Bruix et al. EASL guidelines 2001 [2], with modifications; flow chart (b): from Bruix et al. AASLD guidelines 2005 [3], with modifications; flow-chart (c): from EASL-EORTC guidelines 2012 [4], with modifications.

proposed cut-off value (15 or $50 \mathrm{ng} / \mathrm{mL} / \mathrm{month}$ ) need to be validated $[35,36]$.

\section{Other Biomarkers as Predictors of Survival and Tumor Recurrence}

In the last years, AFP, DCP, and AFP-L3 have been largely investigated with the intent to predict the risk of HCC recurrence after hepatic resection.

A long list of Eastern experiences confirmed the predictive role played by these markers in the preoperative time. A very recent study from Japan has observed that their triple positivity detected before hepatectomy was related to postoperative poor prognosis [11]. A similar analysis performed on 416 patients showed that AFP $>100 \mathrm{ng} / \mathrm{mL}$ and AFP-L3 $>15 \%$ before radiofrequency ablation were significant predictors for the risk of HCC recurrence [37].

The role of doubling time of preoperative AFP and DCP has been also investigated as useful tool for the prediction of early postoperative recurrence [38].

Two Korean studies performed on 126 and 245 resected patients showed that preoperative DCP was superior to AFP in predicting recurrence $[39,40]$. In fact, recent researches have demonstrated that DCP stimulates human vascular endothelial cell growth and tumor migration, in this way explaining its important role as predictor of survival and recurrence [41]. As a confirmation, DCP was more specific for the detection of vascular invasion, whilst AFP-L3 was related to progression from moderately differentiated to poorly differentiated HCC [42].

Despite the large number of experiences reported, it is clear that not all the studies are in agreement among them: larger and possibly multicentre studies are needed with the intent to test the pre-operative role of these markers on a large cohort of patients, in this way avoiding the possible biases of patient selection.

Apart from their pre-operative detection, postoperative markers also showed a strong connection with HCC recurrence, even presenting in some cases a direct correlation between their value at recurrence and the site of recurrence [43].

Nanashima et al. observed that normalization of DCP after hepatectomy was significantly associated with good patient survival, in this way reflecting the efficacy of the treatment [44].

Postoperative DCP values appeared more closely associated with indices of tumor invasiveness like tumor large 
dimension, vascular invasion, intrahepatic metastases, and a lower grade of tumor cell differentiation [45]. One study performed on 124 patients treated with termoablation showed that posttreatment AFP-L3 resulted in the most reliable tumor marker for estimating overall survival and disease-free survival respect to AFP and DCP [46].

Despite the good results observed in all the reported studies, a recent report from the University of Nagasaki performed on 470 patients treated for HCC showed conflicting results, concluding that high AFP or DCP levels did not sufficiently reflect curative efficacy of treatment: hence, the authors affirmed AFP and DCP were poor predictors of prognosis in HCC patients [47].

Consequently, also for postoperative markers values, we can obtain the same considerations done for the preoperative ones. A study performed on a large population is needed to better investigate the effective role of postoperative markers modification as predictors of recurrence.

Apart from this, it is very interesting to underline that all the reported studies come from Asia, showing that the use of DCP and AFP-L3 represents a controversial point between Western and Eastern countries in the clinical management of HCC. In fact, despite the optimal results showed by some Eastern experiences, systematic application of these markers looks to be unlikely in European and US clinical practice. Possible explanations for this disagreement may be the poor availability of these new markers in Western countries, or the belief that Asian tumors are biologically different from Western ones and, consequently, with different biological proteins expression.

It is opinion of the authors that a large evaluation of these markers also in the Western scenario is strongly required, with the intent to confirm their power for HCC recurrence prediction.

\section{Use of AFP and Other Markers in HCC Prognostic Staging Systems}

In recent years, different staging systems have been proposed with the intent to better stratify HCC patients. In Japan, biomarkers have been integrated into some of them as selection variables.

For example, the proposed "biomarker combined Japan Integrated Staging (bm-JIS)," proposed in 2008, was invented with the intent to improve the stratification ability of the already existed JIS, in this way adding to the previous prognostic model the possibility of also estimating the HCC malignant grade. A total of 1.924 HCC patients were included in this study, and the three tumor markers AFP, AFP-L3, and DCP, were used. The stratification value of the bm-JIS score was superior to the JIS score, as observed by the higher likelihood ratio test obtained for the first model after Cox regression analysis [48].

Another score, called BALAD score, was developed in 2006. This scoring system was exclusively based on 5 serum markers: bilirubin, albumin, AFP-L3, AFP, and DCP. The system was validated in $2600 \mathrm{HCC}$ patients from 5 institutions. The discriminative ability of the model resulted was excellent, adding the great advantage of being easy to perform [49].

Also in these cases, despite the large populations analyzed and the excellent ability in cohort stratification, the proposed scores need to be confirmed out of Japan, possibly in a Western experience, with the intent to confirm their effective pertinence.

\section{Use of AFP and Other Markers for the Selection of Liver Transplant Candidates}

Use of AFP for the selection of LT candidates has recently observed a progressive increase. In a recent analysis performed on national data from the USA, transplanted HCC patients with moderately or highly elevated AFP levels presented poor results after LT. Moreover, patients with similar sized tumors but elevated AFP levels still had worse survival, showing that AFP seems to be a better surrogate for bad biology than size $[50,51]$.

In a very recent study from Europe, it has been clearly reported that "use of changes in serum levels of biomarkers for assessment of response (i.e., AFP levels) is under investigation" [4]; similarly, the US national conference for liver allocation in HCC patients has established that "allocation points will be based on a candidate's calculated MELD score plus the following factors.

(a) $A F P<500 \mathrm{ng} / \mathrm{mL}$.

(b) Tumor size within the Milan Criteria (MC).

(c) Time within the MC (this includes patients downstaged to within the MC).

(d) No points will be added if the AFP level is greater than $500 \mathrm{ng} / \mathrm{mL} . "$ [34].

As previously reported, studies from Italy, Switzerland, the USA, Canada, and France have been recently published, all of them underlying the role of AFP as predictor of survival and recurrence during the waiting time $[25,26,33,35,36]$.

Combination of radiology and biology for the selection of LT candidates has been strongly proposed, in this way investigating not only the morphological features of the tumor, but also its biological aggressiveness (Table 1).

A study from North America has proposed the combination of total tumor volume (TTV) $<115 \mathrm{~cm}^{3}$ and AFP $<400 \mathrm{ng} / \mathrm{mL}$ for the selection of HCC patients, showing that patients exceeding these cut-offs presented very poor post-LT results (below $50 \%$ at 3 years) [33].

In another study from the Inter-University Consortium of Rome, 158 HCC patients were stratified according to the total tumor diameter (TTD) $>8 \mathrm{~cm}$ and AFP $>400 \mathrm{ng} / \mathrm{mL}$. At multivariate analysis, both these variables were the unique independent risk factors for recurrence, presenting the AFP value $>400 \mathrm{ng} / \mathrm{mL}$ an 8 -fold increased risk for developing post-LT HCC recurrence. Radiological-biological combination consented to obtain a better selection of candidates for LT without worsening patient survival and recurrence rates, this approach allowing for an increase in the number of potentially transplantable patients [67]. 
TABLE 1: Various proposed criteria for the selection of HCC patients waiting for liver transplantation.

\begin{tabular}{lc}
\hline Author (year), abbreviation & Criteria \\
\hline Mazzaferro [52], Milan & Only radiological criteria \\
Yao [53], UCSF & $1 \mathrm{HCC} \leq 5 \mathrm{~cm}$ or $\leq 3 \mathrm{HCC} \leq 3 \mathrm{~cm}$ \\
Herrero [54], CUN & $1 \mathrm{HCC} \leq 6.5 \mathrm{~cm}$ or $\leq 3 \mathrm{HCC} \leq 4.5 \mathrm{~cm}$ with TTD $\leq 8 \mathrm{~cm}$ \\
Onaca [55], Dallas & $1 \mathrm{HCC} \leq 6 \mathrm{~cm}$ or $\leq 3 \mathrm{HCC} \leq 5 \mathrm{~cm}$ \\
Sugawara [56], Tokyo & $1 \mathrm{HCC} \leq 6 \mathrm{~cm}$ or $\leq 4 \mathrm{HCC} \leq 5 \mathrm{~cm}$ \\
Lee [57], Asan & $\leq 5 \mathrm{HCC} \leq 5 \mathrm{~cm}$ \\
Silva [58], Valencia & $\leq 6 \mathrm{HCC} \leq 5 \mathrm{~cm}$ \\
Toso [59], TTV & $\leq 3 \mathrm{HCC} \leq 5 \mathrm{~cm}$ with TTD $\leq 10 \mathrm{~cm}$ \\
Mazzaferro [60], Up-to-seven & TTV $\leq 115 \mathrm{~cm}{ }^{3}$ \\
Fan [61], Shanghai & Number + maximum size of HCC $=7$ \\
& $1 \mathrm{HCC} \leq 9 \mathrm{~cm}$ or $\leq 3 \mathrm{HCC} \leq 5 \mathrm{~cm} \mathrm{with} \mathrm{TTD} \leq 9 \mathrm{~cm}$ \\
\hline Cillo [62], Padua & Criteria needing preoperative biopsy \\
Zheng [63], Hangzhou & Tumor grading I or II \\
\hline & TTD $\leq 8 \mathrm{~cm}$ or HCC grading or II and AFP $\leq 400 \mathrm{ng} / \mathrm{mL}$ \\
\hline Kwon [64], Seoul & Combined radiological and biological criteria \\
Takada , Ito [65, 66], Kyoto & HCC $\leq 5 \mathrm{~cm}$ (no number restriction) and AFP $\leq 400 \mathrm{ng} / \mathrm{mL}$ \\
Toso et al. [33], TTV/AFP & $\leq 10 \mathrm{HCC} \leq 5 \mathrm{~cm}$ and DCP $\leq 400 \mathrm{mAU} / \mathrm{mL}$ \\
Lai et al. [67], TTD/AFP & TTV $\leq 115 \mathrm{~cm}{ }^{3}$ and AFP $\leq 400 \mathrm{ng} / \mathrm{mL}$ \\
\hline
\end{tabular}

HCC: hepatocellular carcinoma; TTD: total tumor diameter; TTV: total tumor volume; AFP: alpha foetoprotein; DCP: des- $\gamma$-carboxy prothrombin.

Apart from AFP, also the other markers were used in LT: a study from Japan performed on 456 patients who underwent LT showed that the elevation of AFP-L3 $(P=0.0171)$ and DCP $(P=0.0004)$ significantly affected decreased survival rate and that DCP elevation had the strongest effect on patient survival [68].

In a study from Kyoto performed on 144 patients who underwent living donor LT, multivariate analysis revealed that tumor size $>5 \mathrm{~cm},>$ or $=11$ nodules, and DCP $>400 \mathrm{mAU} / \mathrm{mL}$ were significant independent risk factors for recurrence. The so-called Kyoto criteria were then developed according to these variables, consenting to obtain additional information regarding histological features and thus greatly improving patient selection criteria [69].

The recent progression in the number of studies focalized on the role of biological markers as selectors of patients waiting for LT strongly suggests that morphological aspects alone (i.e., tumor number and dimensions) are not fully able to select patients. Large national studies (mainly from North America) have been already performed, but an international validation of these new criteria is still needed, being nowadays MC (exclusively based on morphological aspects) the unique real criteria clearly recognized worldwide.

\section{The Future}

Until now, an HCC molecular classification does not exist. In fact, HCC represents a complex and heterogeneous tumor with several genomic alterations. Many studies reported several aberrant activations of signaling cascades such as vascular endothelial and epidermal growth factor receptors (VEGFR and EGFR), Ras/extracellular signalregulated kinase, phosphoinositol 3-kinase/mammalian target of rapamycin (mTOR), hepatocyte growth factor/ mesenchymal-epithelial transition factor, Wnt, Hedgehog, and apoptotic signaling [70].

The recent introduction in the clinical practice of mTOR inhibitors and, mainly, sorafenib, as molecular therapies against HCC, has focalized on the attention on new plasma biological markers [71, 72].

However, an exponential increase in the number of new discovered proteins involved in tumor differentiation and aggressiveness has been observed in the very recent last years, further underlining the great complexity of HCC genomics and the difficulties existent in this area of research.

In a recent analysis from the Sorafenib HCC Assessment Randomized Protocol (SHARP) trial, ten plasma biomarkers were tested in 491 patients [73]: two angiogenesis biomarkers (Ang2 and VEGF) were independent predictors of survival in patients with advanced HCC.

VEGF and its receptor (VEGF-R) seem to be extremely important in tumor aggressiveness, because of their angiogenetic role: VEGF represents the target molecule of sorafenib, the most important anti-HCC drug developed in the last years.

Consequently, several studies have underlined the critical role of VEGF. In a study from Italy, a direct correlation between high AFP values and VEGF protein expression was reported [74]. Similarly, AFP mRNA and VEGFR-1 mRNA from the bone marrow and peripheral blood of 114 Japanese patients treated with primary curative hepatectomy showed a strong correlation of their concentration with the risk of early recurrence after surgical treatment [75]. 
The direct research of VEGFR expression in cell lines and specimens represents another attractive approach for investigating its role. High expression of VEGFR-1 was detected in 4 HCC cell lines and in the samples of 95 HCC patients treated with curative resection, resulting in an independent prognostic factor for recurrence and overall survival [76].

Besides the role of the new biomarkers evaluable from plasma or directly from the tumor tissue, global gene expression profiling may represent the most appropriate technology to unravel the pathogenesis of HCC and explore its heterogeneous origin [77]. In fact, it is very well known, as reported in a recent review by Marsh and Schmidt [78], that "In the field of surgical oncology, tumor biology is king, patient selection is queen, and technical maneuvers are the prince and princess who try, but usually fail, to usurp the throne."

Unfortunately, although these investigations represent a promising progress in the field of prognostic prediction for HCC, their immediate application in the clinical practice is hindered by the great inhomogeneity existent among HCCs: in fact, a sort of "Babel" of different genetic subgroups exist according to etiological factors, tumor stages, recurrence and survival [79].

Recently, a real biobanking protocol has been established, with the intent to investigate whole genome sequencing, exome sequencing, gene-specific analysis, gene expression, and epigenetic analysis of HCC patients [80].

In the last decade, preliminary studies have been performed in both Western and Eastern centers.

In 2003, Marsh et al. [81] proposed the use of a panel of tumor suppressor gene markers of allelic loss to better investigate the risk of tumor recurrence after LT. Loss of heterozygosity of specific genes of interest (APC, CDKN2A, DCC, MET, MYC1, OGG1, p34, p53, PTEN) was investigated in 103 different HCC patients. An index based on the fractional allelic imbalance (FAI) rate was constructed, showing a strongly accurate prediction for tumor recurrence.

FAI index was successively tested on 183 HCC patients who underwent LT [82], resulting the strongest predictor of post-LT recurrence, followed by vascular invasion and morphological aspects (tumor number and bilobar involvement).

Another study from the USA observed a gene signature based on 406 different genes able to discriminate two populations of good and poor survivals among HBV patients [83]. The same group, more recently, reported an additional hepatoblastoma-like HCC subgroup with very poor prognosis [84].

Other studies, using different genes, reported similar abilities in predicting patient and disease-free survivals and excellent accuracies [85-87]: for example, a Japanese study performed on 60 patients and based on a 12-gene signature identified through high-density oligonucleotide microarrays (>6000 genes) reported an accuracy above 90\% [86].

A recent analysis performed on 214 resected patients, defined a gene-expression signature associated with the prediction of vascular invasion (accuracy: 69\%) [88].
The recent discovery of RNA interference has further revolutionized the "loss of function genetics": miRNA-based delivery strategies have shown antitumoral activity in HCC animal models, and dysregulation of miRNA has also proved high prognostic predictive value in human samples [89]. The use of reversible miRNA against P53 tumor suppressor has recently enabled the identification of P53 loss as a major requirement for the maintenance of murine liver carcinoma. Similar miRNA-based approaches were recently used to functionally validate DLC-1 as a tumor suppressor included in $8 \mathrm{p}$, a chromosomal region that is found deleted in up to $50 \%$ of human HCC.

The advent of further novel technologies, such as deep sequencing and integrative genomic analysis, and the consolidation of sophisticated animal models (mosaic models, transposons) will represent the beginning of a new era in cancer gene discovery.

However, despite the surprising results reported using genomics and new target proteins involved in HCC pathways, a long time is still required before their routine use in clinical and surgical practice: the experience with sorafenib is still at the beginning, and new drugs will be developed in the next future. Larger validation of genetic aspects on international cohorts and common genetic markers between Western and Eastern patients are still required.

\section{Conclusions}

Biomarkers routinely used for HCC detection are suboptimal tests for routine clinical practice in HCC diagnosis. New and more accurate biomarkers for early HCC detection need to be already developed. On the contrary, these markers are routinely and successfully used as predictors of survival and HCC recurrence in patients treated with curative intent, mainly in Eastern countries. On these bases, the development of a predictive model combining radiological and biological features is strongly suggested. Use of AFP modification during the waiting list for LT is still under investigation. New genetic markers are continuously discovered, but their use is not already routinely available in the clinical practice.

\section{Conflict of Interests}

The authors have no conflict of interests to declare.

\section{References}

[1] H. Tsukuma, T. Hiyama, S. Tanaka et al., "Risk factors for hepatocellular carcinoma among patients with chronic liver disease," The New England Journal of Medicine, vol. 328, no. 25, pp. 1797-1801, 1993.

[2] J. Bruix, M. Sherman, J. M. Llovet et al., "Clinical management of hepatocellular carcinoma. Conclusions of the barcelona2000 EASL conference," Journal of Hepatology, vol. 35, no. 3, pp. 421-430, 2001.

[3] J. Bruix and M. Sherman, "Management of hepatocellular carcinoma," Hepatology, vol. 42, no. 5, pp. 1208-1236, 2005. 
[4] European Association for the Study of the Liver and European Organisation for Research and Treatment of Cancer, "EASLEORTC clinical practice guidelines: management of hepatocellular carcinoma," Journal of Hepatology, vol. 56, pp. 908 943, 2012.

[5] R. K. Sterling, E. C. Wright, T. R. Morgan et al., "Frequency of elevated hepatocellular carcinoma (HCC) biomarkers in patients with advanced hepatitis C," American Journal of Gastroenterology, vol. 107, no. 1, pp. 64-74, 2012.

[6] G. Bertino, A. M. Ardiri, M. M. Santonocito, and P. M. Boemi, "Some patients with HCC haven't abnornormal desgamma-carboxy prothrombin and alpha-fetoprotein levels," Panminerva Medica, vol. 51, no. 2, pp. 133-134, 2009.

[7] T. Yamashita, M. Forgues, W. Wang et al., "EpCAM and $\alpha$ fetoprotein expression defines novel prognostic subtypes of hepatocellular carcinoma," Cancer Research, vol. 68, no. 5, pp. 1451-1461, 2008.

[8] F. Trevisani, P. E. D'Intino, A. M. Morselli-Labate et al., "Serum $\alpha$-fetoprotein for diagnosis of hepatocellular carcinoma in patients with chronic liver disease: influence of HBsAg and anti-HCV status," Journal of Hepatology, vol. 34, no. 4, pp. 570-575, 2001.

[9] A. Forner, M. Reig, and J. Bruix, " $\alpha$-fetoprotein for hepatocellular carcinoma diagnosis: the demise of a brilliant star," Gastroenterology, vol. 137, no. 1, pp. 26-29, 2009.

[10] M. L. Volk, J. C. Hernandez, G. L. Su, A. S. Lok, and J. A. Marrero, "Risk factors for hepatocellular carcinoma may impair the performance of biomarkers: a comparison of AFP, DCP, and AFP-L3," Cancer Biomarkers, vol. 3, no. 2, pp. 79-87, 2007.

[11] S. Kiriyama, K. Uchiyama, M. Ueno et al., "Triple positive tumor markers for hepatocellular carcinoma are useful predictors of a poor survival," Annals of Surgery, vol. 254, pp. 984 991, 2011.

[12] A. S. Lok, R. K. Sterling, J. E. Everhart et al., "Des- $\gamma$-carboxy prothrombin and $\alpha$-fetoprotein as biomarkers for the early detection of hepatocellular carcinoma," Gastroenterology, vol. 138, no. 2, pp. 493-502, 2010.

[13] Y. Inagaki, W. Tang, M. Makuuchi, K. Hasegawa, Y. Sugawara, and N. Kokudo, "Clinical and molecular insights into the hepatocellular carcinoma tumour marker des- $\gamma$ carboxyprothrombin," Liver International, vol. 31, no. 1, pp. 22-35, 2011.

[14] G. Bertino, A. M. Ardiri, P. M. Boemi et al., "A study about mechanisms of des-gamma-carboxy prothrombin's production in hepatocellular carcinoma," Panminerva Medica, vol. 50, no. 3, pp. 221-226, 2008.

[15] B. I. Carr, Z. Wang, M. Wang, and G. Wei, "Differential effects of vitamin K1 on AFP and DCP levels in patients with unresectable HCC and in HCC cell lines," Digestive Diseases and Sciences, vol. 56, no. 6, pp. 1876-1883, 2011.

[16] B. Sharma, R. Srinivasan, Y. K. Chawla et al., "Clinical utility of prothrombin induced by vitamin $\mathrm{K}$ absence in the detection of hepatocellular carcinoma in Indian population," Hepatology International, vol. 4, no. 3, pp. 569-576, 2010.

[17] Y. H. Baek, J. H. Lee, J. S. Jang et al., "Diagnostic role and correlation with staging systems of PIVKA-II compared with AFP," Hepato-Gastroenterology, vol. 56, no. 91-92, pp. 763767, 2009.

[18] F. A. Durazo, L. M. Blatt, W. G. Corey et al., "Des- $\gamma$ carboxyprothrombin, $\alpha$-fetoprotein and AFP-L3 in patients with chronic hepatitis, cirrhosis and hepatocellular carcinoma," Journal of Gastroenterology and Hepatology, vol. 23, no. 10, pp. 1541-1548, 2008.
[19] J. A. Marrero, Z. Feng, Y. Wang et al., " $\alpha$-fetoprotein, des- $\gamma$ carboxyprothrombin, and lectin-bound $\alpha$-fetoprotein in early hepatocellular carcinoma," Gastroenterology, vol. 137, no. 1, pp. 110-118, 2009.

[20] R. K. Sterling, L. Jeffers, F. Gordon et al., "Utility of Lens culinaris agglutinin-reactive fraction of $\alpha$-fetoprotein and desGamma-carboxy prothrombin, alone or in combination, as biomarkers for hepatocellular carcinoma," Clinical Gastroenterology and Hepatology, vol. 7, no. 1, pp. 104-113, 2009.

[21] G. Beale, D. Chattopadhyay, J. Gray et al., "AFP, PIVKAII, GP3, SCCA-1 and follisatin as surveillance biomarkers for hepatocellular cancer in non-alcoholic and alcoholic fatty liver disease," BMC Cancer, vol. 8, article 200, 2008.

[22] B. I. Carr, F. Kanke, M. Wise, and S. Satomura, "Clinical evaluation of Lens culinaris agglutinin-reactive $\alpha$-fetoprotein and des- $\gamma$-carboxy prothrombin in histologically proven hepatocellular carcinoma in the United States," Digestive Diseases and Sciences, vol. 52, no. 3, pp. 776-782, 2007.

[23] Y. Koike, Y. Shiratori, S. Sato, S. Obi, T. Teratani et al., "Desgammacarboxy prothrombin as a useful predisposing factor for the development of portal venous invasion in patients with hepatocellular carcinoma: a prospective analysis of 227 patients," Cancer, vol. 91, pp. 561-569, 2001.

[24] R. K. Sterling, L. Jeffers, F. Gordon et al., "Clinical utility of AFP-L3\% measurement in North American patients with HCV-related cirrhosis," American Journal of Gastroenterology, vol. 102, no. 10, pp. 2196-2205, 2007.

[25] S. Merani, P. Majno, N. M. Kneteman et al., "The impact of waiting list alpha-fetoprotein changes on the outcome of liver transplant for hepatocellular carcinoma," Journal of Hepatology, vol. 55, pp. 814-819, 2011.

[26] Q. Lai, A. W. Avolio, T. M. Manzia et al., "Role of alphafetoprotein in selection of patients with hepatocellular carcinoma waiting for liver transplantation: must we reconsider it?" International Journal of Biological Markers, vol. 26, no. 3, pp. 153-159, 2011.

[27] M. C. Tsai, J. H. Wang, C. H. Hung et al., "Favorable $\alpha$ fetoprotein decrease as a prognostic surrogate in patients with hepatocellular carcinoma after radiofrequency ablation," Journal of Gastroenterology and Hepatology, vol. 25, no. 3, pp. 605-612, 2010.

[28] Y. Y. Shao, Z. Z. Lin, C. Hsu, Y. C. Shen, C. H. Hsu, and A. L. Cheng, "Early alpha-fetoprotein response predicts treatment efficacy of antiangiogenic systemic therapy in patients with advanced hepatocellular carcinoma," Cancer, vol. 116, no. 19, pp. 4590-4596, 2010.

[29] S. L. Chan, F. K. F. Mo, P. J. Johnson et al., "New utility of an old marker: serial $\alpha$-fetoprotein measurement in predicting radiologic response and survival of patients with hepatocellular carcinoma undergoing systemic chemotherapy," Journal of Clinical Oncology, vol. 27, no. 3, pp. 446-452, 2009.

[30] Q. Lai, M. Merli, S. Ginanni Corradini et al., "Predictive factors of recurrence of hepatocellular carcinoma after liver transplantation: a multivariate analysis," Transplantation Proceedings, vol. 41, no. 4, pp. 1306-1309, 2009.

[31] U. Cillo, A. Vitale, F. Navaglia et al., "Role of blood AFP mRNA and tumor grade in the preoperative prognostic evaluation of patients with hepatocellular carcinoma," World Journal of Gastroenterology, vol. 11, no. 44, pp. 6920-6925, 2005.

[32] M. Iavarone, P. Lampertico, G. Ronchi, E. Del Ninno, A. Zanella, and M. Colombo, "A prospective study of blood alpha-fetoprotein messenger $\mathrm{RNa}$ as a predictor of hepatocellular carcinoma in patients with cirrhosis," Journal of Viral Hepatitis, vol. 10, no. 6, pp. 423-426, 2003. 
[33] C. Toso, S. Asthana, D. L. Bigam, A. M. J. Shapiro, and N. M. Kneteman, "Reassessing selection criteria prior to liver transplantation for hepatocellular carcinoma utilizing the scientific registry of transplant recipients database," Hepatology, vol. 49, no. 3, pp. 832-838, 2009.

[34] E. A. Pomfret, K. Washburn, C. Wald et al., "Report of a national conference on liver allocation in patients with hepatocellular carcinoma in the United States," Liver Transplantation, vol. 16, no. 3, pp. 262-278, 2010.

[35] E. Vibert, D. Azoulay, E. Hoti et al., "Progression of alphafetoprotein before liver transplantation for hepatocellular carcinoma in cirrhotic patients: a critical factor," American Journal of Transplantation, vol. 10, no. 1, pp. 129-137, 2010.

[36] K. Han, G. N. Tzimas, J. S. Barkun et al., "Preoperative alphafetoprotein slope is predictive of hepatocellular carcinoma recurrence after liver transplantation," Canadian Journal of Gastroenterology, vol. 21, no. 1, pp. 39-45, 2007.

[37] R. Tateishi, S. Shiina, H. Yoshida et al., "Prediction of recurrence of hepatocellular carcinoma after curative ablation using three tumor markers," Hepatology, vol. 44, no. 6, pp. 1518-1527, 2006.

[38] T. Masuda, T. Beppu, K. Horino et al., "Preoperative tumor marker doubling time is a useful predictor of recurrence and prognosis after hepatic resection of hepatocellular carcinoma," Journal of Surgical Oncology, vol. 102, no. 5, pp. 490-496, 2010.

[39] S. K. Hyoung, W. P. Ji, S. J. Ji et al., "Prognostic values of $\alpha$-fetoprotein and protein induced by vitamin $\mathrm{K}$ absence or antagonist-II in hepatitis B virus-related hepatocellular carcinoma: a prospective study," Journal of Clinical Gastroenterology, vol. 43, no. 5, pp. 482-488, 2009.

[40] D. Y. Kim, Y. H. Paik, S. H. Ahn et al., "PIVKA-II is a useful tumor marker for recurrent hepatocellular carcinoma after surgical resection,” Oncology, vol. 72, supplement 1, pp. 52$57,2007$.

[41] G. Bertino, A. M. Ardiri, G. S. Calvagno, N. Bertino, and P. M. Boemi, "Prognostic and diagnostic value of des- $\gamma$-carboxy prothrombin in liver cancer," Drug News and Perspectives, vol. 23, no. 8, pp. 498-508, 2010.

[42] H. Miyaaki, O. Nakashima, M. Kurogi, K. Eguchi, and M. Kojiro, "Lens culinaris agglutinin-reactive $\alpha$-fetoprotein and protein induced by vitamin $\mathrm{K}$ absence II are potential indicators of a poor prognosis: a histopathological study of surgically resected hepatocellular carcinoma," Journal of Gastroenterology, vol. 42, no. 12, pp. 962-968, 2007.

[43] K. Yamamoto, H. Imamura, Y. Matsuyama et al., "Significance of alpha-fetoprotein and des- $\gamma$-carboxy prothrombin in patients with hepatocellular carcinoma undergoing hepatectomy," Annals of Surgical Oncology, vol. 16, no. 10, pp. 27952804, 2009.

[44] A. Nanashima, Y. Sumida, S. Tobinaga et al., "Postoperative changes in protein-induced vitamin $\mathrm{K}$ absence or antagonist II levels after hepatectomy in patients with hepatocellular carcinoma: relationship to prognosis," Journal of the International Hepato Pancreato Biliary Association, vol. 8, no. 2, pp. 137-141, 2006.

[45] K. Yamamoto, H. Imamura, Y. Matsuyama et al., "AFP, AFPL3, DCP, and GP73 as markers for monitoring treatment response and recurrence and as surrogate markers of clinicopathological variables of HCC," Journal of Gastroenterology, vol. 45, no. 12, pp. 1272-1282, 2010.

[46] C. Ogawa, M. Kudo, Y. Minami, H. Chung, and T. Kawasaki, "Tumor markers after radiofrequency ablation therapy for hepatocellular carcinoma," Hepato-Gastroenterology, vol. 55, no. 85, pp. 1454-1457, 2008.
[47] A. Nanashima, N. Taura, T. Abo et al., "Tumor marker levels before and after curative treatment of hepatocellular carcinoma as predictors of patient survival," Digestive Diseases and Sciences, vol. 56, pp. 3086-3100, 2011.

[48] S. Kitai, M. Kudo, Y. Minami et al., "A new prognostic staging system for hepatocellular carcinoma: value of the biomarker combined Japan integrated staging score," Intervirology, vol. 51, supplement 1, pp. 86-94, 2008.

[49] H. Toyoda, T. Kumada, Y. Osaki et al., "Staging hepatocellular carcinoma by a novel scoring system (BALAD score) based on serum markers," Clinical Gastroenterology and Hepatology, vol. 4, no. 12, pp. 1528-1536, 2006.

[50] B. Mailey, A. Artinyan, J. Khalili et al., "Evaluation of absolute serum $\alpha$-fetoprotein levels in liver transplant for hepatocellular cancer," Archives of Surgery, vol. 146, no. 1, pp. 26-33, 2011.

[51] A. M. Cameron, "AFP in OLT for HCC? Another shadow on the cave wall: comment on 'evaluation of absolute serum $\alpha$ fetoprotein levels in liver transplant for hepatocellular cancer'”, Archives of Surgery, vol. 146, no. 1, pp. 33-34, 2011.

[52] V. Mazzaferro, E. Regalia, R. Doci et al., "Liver transplantation for the treatment of small hepatocellular carcinomas in patients with cirrhosis," The New England Journal of Medicine, vol. 334, no. 11, pp. 693-699, 1996.

[53] F. Y. Yao, L. Ferrell, N. M. Bass et al., "Liver transplantation for hepatocellular carcinoma: expansion of the tumor size limits does not adversely impact survival," Hepatology, vol. 33, no. 6, pp. 1394-1403, 2001.

[54] J. I. Herrero, B. Sangro, J. Quiroga et al., "Influence of tumor characteristics on the outcome of liver transplantation among patients with liver cirrhosis and hepatocellular carcinoma," Liver Transplantation, vol. 7, no. 7, pp. 631-636, 2001.

[55] N. Onaca, G. L. Davis, R. M. Goldstein, L. W. Jennings, and G. B. Klintmalm, "Expanded criteria for liver transplantation in patients with hepatocellular carcinoma: a report from the international registry of hepatic tumors in liver transplantation," Liver Transplantation, vol. 13, no. 3, pp. 391-399, 2007.

[56] Y. Sugawara, S. Tamura, and M. Makuuchi, "Living donor liver transplantation for hepatocellular carcinoma: Tokyo University series," Digestive Diseases, vol. 25 , no. 4 , pp. 310 312, 2007.

[57] S. G. Lee, S. Hwang, D. B. Moon et al., "Expanded indication criteria of living donor liver transplantation for hepatocellular carcinoma at one large-volume center," Liver Transplantation, vol. 14, no. 7, pp. 935-945, 2008.

[58] M. Silva, A. Moya, M. Berenguer et al., "Expanded criteria for liver transplantation in patients with cirrhosis and hepatocellular carcinoma," Liver Transplantation, vol. 14, no. 10, pp. 1449-1460, 2008.

[59] C. Toso, J. Trotter, A. Wei et al., "Total tumor volume predicts risk of recurrence following liver transplantation in patients with hepatocellular carcinoma," Liver Transplantation, vol. 14, no. 8, pp. 1107-1115, 2008.

[60] V. Mazzaferro, J. M. Llovet, R. Miceli et al., "Predicting survival after liver transplantation in patients with hepatocellular carcinoma beyond the Milan criteria: a retrospective, exploratory analysis," The Lancet Oncology, vol. 10, no. 1, pp. 35-43, 2009.

[61] J. Fan, G. S. Yang, Z. R. Fu et al., "Liver transplantation outcomes in 1,078 hepatocellular carcinoma patients: a multicenter experience in Shanghai, China," Journal of Cancer Research and Clinical Oncology, vol. 135, no. 10, pp. 14031412, 2009. 
[62] U. Cillo, A. Vitale, M. Bassanello et al., "Liver transplantation for the treatment of moderately or well-differentiated hepatocellular carcinoma," Annals of Surgery, vol. 239, no. 2, pp. 150-159, 2004.

[63] S. S. Zheng, X. Xu, J. Wu et al., "Liver transplantation for hepatocellular carcinoma: Hangzhou experiences," Transplantation, vol. 85, no. 12, pp. 1726-1732, 2008.

[64] C. H. D. Kwon, D. J. Kim, Y. S. Han et al., "HCC in living donor liver transplantation: can we expand the Milan criteria?" Digestive Diseases, vol. 25, no. 4, pp. 313-319, 2007.

[65] Y. Takada, T. Ito, M. Ueda et al., "Living donor liver transplantation for patients with HCC exceeding the Milan criteria: a proposal of expanded criteria," Digestive Diseases, vol. 25, no. 4, pp. 299-302, 2007.

[66] T. Ito, Y. Takada, M. Ueda et al., "Expansion of selection criteria for patients with hepatocellular carcinoma in living donor liver transplantation," Liver Transplantation, vol. 13, no. 12, pp. 1637-1644, 2007.

[67] Q. Lai, A. W. Avolio, T. M. Manzia et al., "Combination of biological and morphological parameters for the selection of patients with hepatocellular carcinoma waiting for liver transplantation," Clinical Transplantation, vol. 26, no. 2, pp. E125-E131, 2012.

[68] H. Toyoda, T. Kumada, Y. Kaneoka et al., "Prognostic value of pretreatment levels of tumor markers for hepatocellular carcinoma on survival after curative treatment of patients with HCC," Journal of Hepatology, vol. 49, no. 2, pp. 223-232, 2008.

[69] M. Fujiki, Y. Takada, Y. Ogura et al., "Significance of Desgamma-carboxy prothrombin in selection criteria for living donor liver transplantation for hepatocellular carcinoma," American Journal of Transplantation, vol. 9, no. 10, pp. 23622371, 2009.

[70] J. M. Llovet and J. Bruix, "Molecular targeted therapies in hepatocellular carcinoma," Hepatology, vol. 48, no. 4, pp. 1312-1327, 2008.

[71] A. A. Schnitzbauer, C. Zuelke, C. Graeb et al., "A prospective randomised, open-labeled, trial comparing sirolimuscontaining versus mTOR-inhibitor-free immunosuppression in patients undergoing liver transplantation for hepatocellular carcinoma," BMC Cancer, vol. 10, article 190, 2010.

[72] J.-L. Raoul, J. Bruix, T. F. Greten et al., "Relationship between baseline hepatic status and outcome, and effect of sorafenib on liver function: SHARP trial subanalyses," Journal of Hepatology, vol. 56, no. 5, pp. 1080-1088, 2012.

[73] J. M. Llovet, C. E. A. Peña, C. D. Lathia, M. Shan, G. Meinhardt, and J. Bruix, "Plasma biomarkers as predictors of outcome in patients with advanced hepatocellular carcinoma," Clinical Cancer Research, vol. 18, no. 8, pp. 2290-2300, 2012.

[74] S. G. Corradini, S. Morini, F. Liguori et al., "Differential vascular endothelial growth factor A protein expression between small hepatocellular carcinoma and cirrhosis correlates with serum vascular endothelial growth factor $\mathrm{A}$ and $\alpha$ fetoprotein," Liver International, vol. 29, no. 1, pp. 103-112, 2009.

[75] T. Kamiyama, M. Takahashi, K. Nakanishi et al., " $\alpha$-fetoprotein, vascular endothelial growth factor receptor-1 and early recurrence of hepatoma," World Journal of Gastroenterology, vol. 18, no. 4, pp. 340-348, 2012.

[76] T. Li, Y. Zhu, W. Ren, S. Xu, Z. Yang, A. Fang et al., "High co-expression of vascular endothelial growth factor receptor1 and Snail is associated with poor prognosis after curative resection of hepatocellular carcinoma," Medical Oncology. In press.
[77] J. M. Llovet and J. Bruix, "Novel advancements in the management of hepatocellular carcinoma in 2008," Journal of Hepatology, vol. 48, no. 1, pp. S20-S37, 2008.

[78] J. W. Marsh and C. Schmidt, "The Milan criteria: no room on the metro for the king?” Liver Transplantation, vol. 16, no. 3, pp. 252-255, 2010.

[79] E. R. Lemmer, S. L. Friedman, and J. M. Llovet, "Molecular diagnosis of chronic liver disease and hepatocellular carcinoma: the potential of gene expression profiling," Seminars in Liver Disease, vol. 26, no. 4, pp. 373-384, 2006.

[80] T. R. Harring, J. J. Guiteau, N. T. T. Nguyen et al., "Building a comprehensive genomic program for hepatocellular carcinoma," World Journal of Surgery, vol. 35, pp. 1746-1750, 2011.

[81] J. W. Marsh, S. D. Finkelstein, A. J. Demetris et al., "Genotyping of hepatocellular carcinoma in liver transplant recipients adds predictive power for determining recurrencefree survival," Liver Transplantation, vol. 9, no. 7, pp. 664-671, 2003.

[82] I. Dvorchik, M. Schwartz, M. I. Fiel, S. D. Finkelstein, and J. W. Marsh, "Fractional allelic imbalance could allow for the development of an equitable transplant selection policy for patients with hepatocellular carcinoma," Liver Transplantation, vol. 14, no. 4, pp. 443-450, 2008.

[83] J. S. Lee, I. S. Chu, J. Heo et al., "Classification and prediction of survival in hepatocellular carcinoma by gene expression profiling," Hepatology, vol. 40, no. 3, pp. 667-676, 2004.

[84] J. S. Lee, J. Heo, L. Libbrecht et al., "A novel prognostic subtype of human hepatocellular carcinoma derived from hepatic progenitor cells," Nature Medicine, vol. 12, no. 4, pp. 410-416, 2006.

[85] Q. H. Ye, L. X. Qin, M. Forgues et al., "Predicting hepatitis $\mathrm{B}$ virus-positive metastatic hepatocellular carcinomas using gene expression profiling and supervised machine learning," Nature Medicine, vol. 9, no. 4, pp. 416-423, 2003.

[86] N. Iizuka, M. Oka, H. Yamada-Okabe et al., "Oligonucleotide microarray for prediction of early intrahepatic recurrence of hepatocellular carcinoma after curative resection," The Lancet, vol. 361, no. 9361, pp. 923-929, 2003.

[87] Y. Kurokawa, R. Matoba, I. Takemasa et al., "Molecular-based prediction of early recurrence in hepatocellular carcinoma," Journal of Hepatology, vol. 41, no. 2, pp. 284-291, 2004.

[88] B. Mínguez, Y. Hoshida, A. Villanueva et al., "Gene-expression signature of vascular invasion in hepatocellular carcinoma," Journal of Hepatology, vol. 55, no. 6, pp. 1325-1331, 2011.

[89] L. Zender, A. Villanueva, V. Tovar, D. Sia, D. Y. Chiang, and J. M. Llovet, "Cancer gene discovery in hepatocellular carcinoma," Journal of Hepatology, vol. 52, no. 6, pp. 921-929, 2010. 


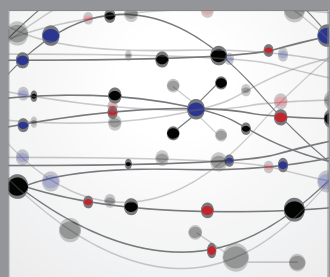

The Scientific World Journal
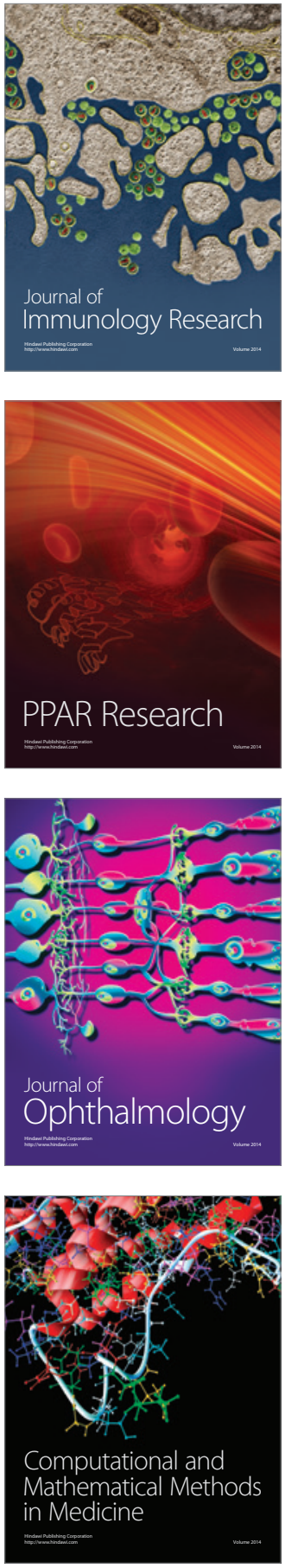

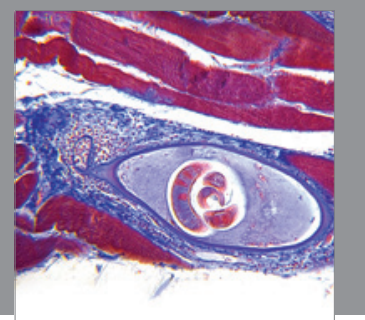

Gastroenterology

Research and Practice
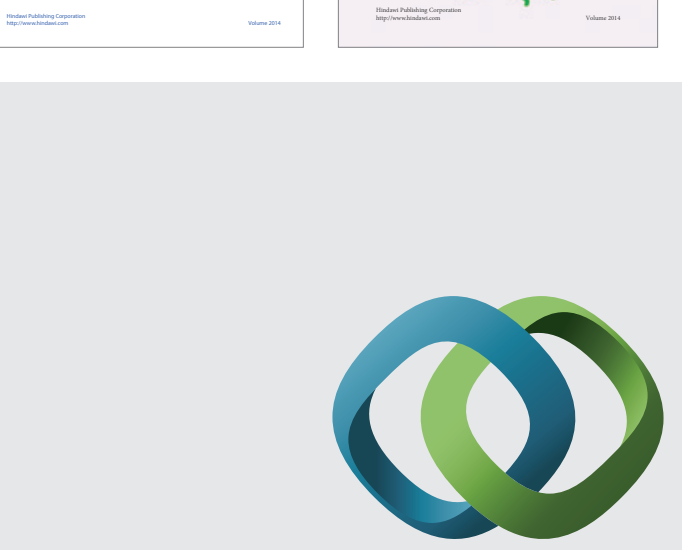

\section{Hindawi}

Submit your manuscripts at

http://www.hindawi.com
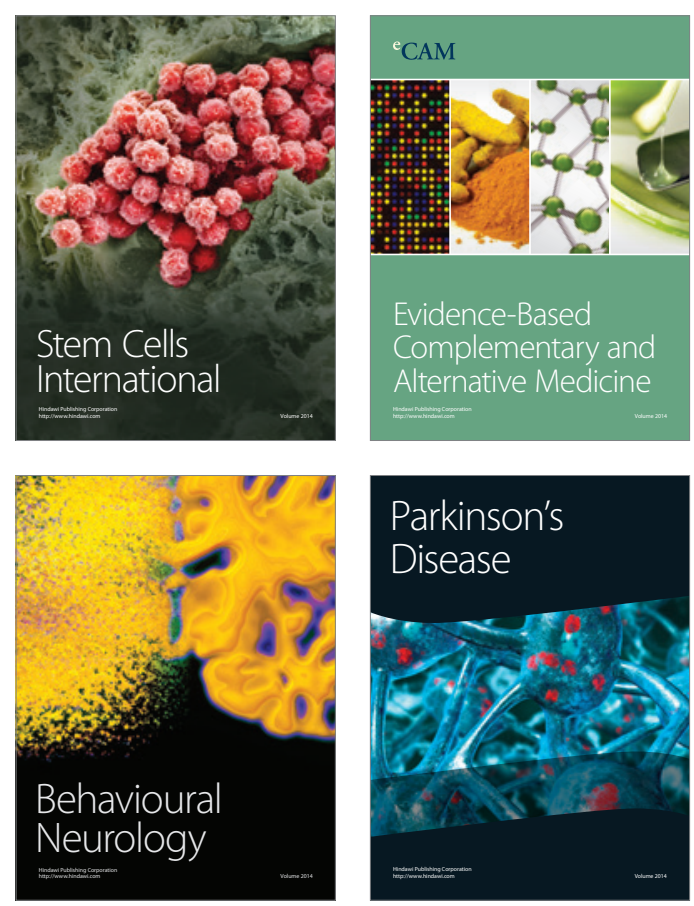

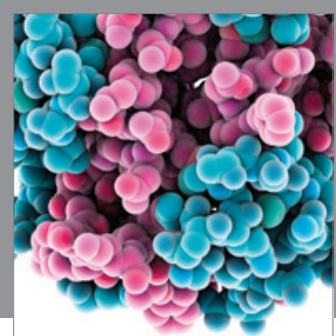

Journal of
Diabetes Research

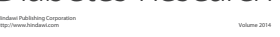

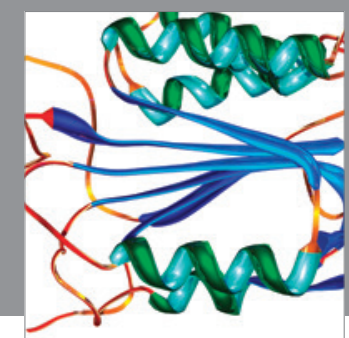

Disease Markers
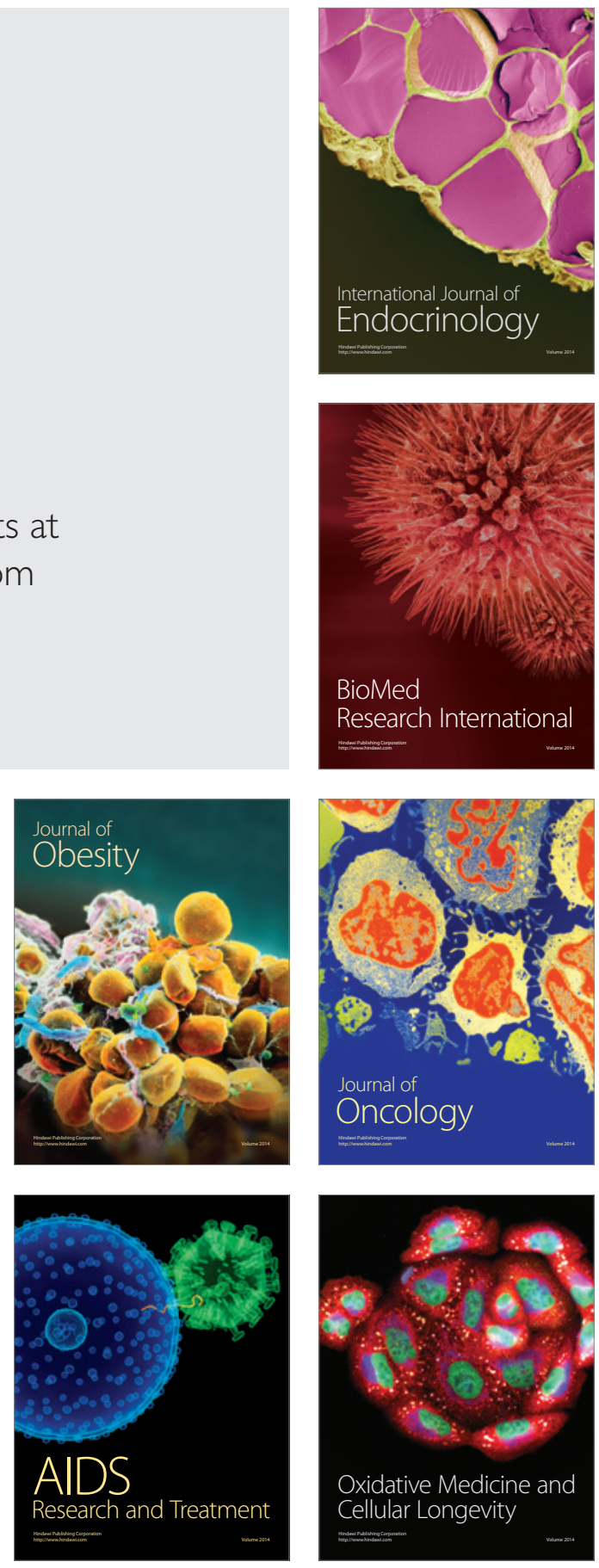